\title{
RECUPERACIÓN QUE TAMBIÉN FUE FINAL
}

\author{
A FINAL RECOVERY \\ RÉCUPÉRER LE POUVOIR POUR LE PERDRE À NOUVEAU \\ LORENZO MEYER \\ El Colegio de México \\ lmeyer@colmex.mx
}

Resumen: Este artículo presenta un análisis general sobre la presidencia de Enrique Peña Nieto, que accedió al poder en 2012 como resultado de la victoria del PRI luego de doce años de gobiernos panistas. Desde el inicio se destaca un elemento central y paradójico que define al sexenio: el pasaje de un arranque avasallante, con el "Pacto por México" y las reformas que surgieron de éste como emblema, a un final en donde la popularidad del presidente cayó a niveles muy bajos y su partido sufrió una derrota sin precedentes. El artículo considera las diferentes "reformas estructurales" derivadas del Pacto, examinando los principales cambios que promovieron, así como la dinámica política que definió su proceso de implementación. Por otro lado, se hace hincapié en dos grandes factores que explicaron el deterioro de la imagen presidencial y del gobierno: uno, los numerosos casos de corrupción en los que se vieron implicados no sólo el presidente y su familia, sino varios gobernadores de su partido; y dos, la escalada de la violencia criminal y el fracaso de la política orientada a combatirla.

Palabras clave: PRI; PAN; democracia; sistema político mexicano; reformas políticas y económicas; futuro.

ABstract: This article presents a general analysis of the presidency of Enrique Peña Nieto, who came to power in 2012 as the result of the PRI victory following twelve years of PAN governments. From the outset a central and paradoxical element of the six-year administration is identified: the passage from a high-impact start to the term, with the "Pact for Mexico" and the emblematic reforms that emerged from this, to an end of term that saw the president's popularity fall to historical lows, and his party suffer an unprecedented defeat. The paper considers the different structural reforms that derived from the 
Pact, examining the principal changes they brought about, together with the political dynamic that defined its implementation process. Meanwhile, emphasis is placed on two major factors that explain the decline in the image of both president and government: one, the numerous cases of corruption which not only implicated the president and his family but also several state governors from his party; secondly the spike in criminal violence and the failure of the policies aimed at fighting it.

Keywords: PRI; PAN; democracy; Mexican political system; political and economic reforms; future.

\section{Traducción de Gonzalo Celorio Morayta}

Résumé: L'article propose un bilan de la présidence d'Enrique Peña Nieto, arrivé au pouvoir en 2012 grâce à la victoire du PRI, après douze années de gouvernements du PAN. Le plus frappant et paradoxal de cette présidence, c'est qu'elle démarre en force, sous le drapeau du Pacte pour le Mexique et des réformes qui en découlent, mais elle s'achève sur l'effondrement de la popularité du président, suivi d'une défaite de son parti comme on n'en avait jamais vue. L'article propose un compte-rendu des «réformes structurelles» émanant du pacte, où l'on évalue les innovations que celui-ci a promues et le jeu politique qui a orienté leur mise en pratique. Deux éléments expliquent la dégradation de l'image présidentielle et du gouvernement, dont le premier concerne les très nombreux cas de corruption impliquant le président et sa famille, ainsi que les gouverneurs des entités fédératives issus du même parti, tandis que le second se rapporte à la vague de violence criminelle et à l'échec de la politique pour l'apaiser.

Mots clefs: PRI, PAN, démocratie, système politique mexicain, réformes politiques et économiques, avenir.

\section{Traducción de BERNARdo Mabire}

Fecha de recepción: junio de 2019

Fecha de aceptación: noviembre de 2019 


\section{DOS ELECGIONES Y UN GRAN CAMBIO}

$\neg$ ras doce años fuera de la residencia presidencial de Los Pinos, la recuperación de la presidencia de México en 2012 por el Partido Revol ucionario Institucional (PRI), con Enrique Peña Nieto (EPN) a la cabeza, resultó ser, también, el acto final de un largo ciclo político mexicano dominado por un partido que nació en 1929, cuando la energía de la Revolución mexicana aún se dejaba sentir. Nueve décadas más tarde, al concluir 2018, el partido creado por el expresidente y general Plutarco Elías Calles aparecía como una fuerza política desprestigiada, derrotada y en camino de convertirse en marginal. ${ }^{1}$

La recuperación de Los Pinos por el PRI, tras derrotar al Partido Acción Nacional (PAN) en 2012, concluyó seis años más tarde de forma dramática: con una apabullante derrota electoral a manos de la izquierda. A su vez, lo que para el viejo partido de Estado fue un desastre, para el sistema político en su conjunto significó la posibilidad de un cambio no sólo de gobierno, sino de aspectos centrales de un régimen político creado y moldeado básicamente por el PRI, por los jefes del ejecutivo salidos de sus filas y por su estilo de ejercer el poder.

Pero volvamos a 2012. La recuperación de la presidencia y del control sobre el gobierno federal por parte del priismo pareció indicar que el grupo encabezado por EPN y con raíces en el Estado de México -entidad siempre gobernada por el PRI y sus antecesores-, volvía a posicionar al partido diseñado por Calles y a su jefe natural, el presidente de la República, como los ejes de la organización política del país por un tiempo transexenal. Y es que ese partido, al que presentó entonces como "el nuevo PRI", se había impuesto de manera

${ }^{1}$ En la encuesta levantada en noviembre de 2019 por Alejandro Moreno y publicada por El Financiero (9 de diciembre de 2019) apenas el $10 \%$ de los encuestados dijo tener una buena opinión del PRI y, en contraste, el $73 \%$ aseguró tener una mala opinión y sólo el $9 \%$ aseguró que de haber elecciones de diputados, votaría por el PRI. 
contundente sobre las fuerzas de derecha que en el año 2000 le arrancaron, vía las urnas, el control que a lo largo de siete décadas había mantenido sobre la presidencia. Después de doce años de panismo, el priismo lo desbancó por un margen sustantivo: $16 \%$. Por otro lado, y aunque con menos contundencia, el PRI también se impuso sobre su otro rival, la izquierda agrupada en el Partido de la Revolución Democrática (PRD), encabezada por Andrés Manuel López Obrador (AMLO). En este último caso, la diferencia en votos no fue abrumadora $(5.6 \%)$, pero sí suficiente para que el triunfo priista no pudiese ser cuestionado con efectividad ante los órganos electorales o la opinión pública, pese a las irregularidades registradas durante la campaña. ${ }^{2}$

Cuando, al finalizar el siglo, en el año 2000, el PRI se vio obligado a abandonar la presidencia, se refugió y se reconstituyó en los estados. ${ }^{3}$ Ahí restañó sus heridas, preservó sus estructuras locales, acumuló recursos -el gobierno panista compró la paz con los gobernadores priistas, que eran mayoría, con la largueza fiscal que le permitieron los altos precios de sus exportaciones petroleras, que en 2000 alcanzaron la suma de 10400 millones de dólares- y políticamente se reagrupó en torno al gobernador con mayores recursos económicos y demográficos: EPN. Salvo por la capital, en 2012, el producto interno bruto (РIB) mexiquense era superior al de cualquiera de las otras entidades federativas y su padrón electoral casi alcanzaba los once millones de ciudadanos: el $13 \%$ del total nacional. ${ }^{4}$ Además, el PRI mexiquense mantenía un carácter particularmente compacto y disciplinado.

${ }^{2}$ La irregularidad más notoria fue la falta de control sobre el gasto de los partidos. María Amparo Casar y Luis Carlos Ugalde, Dinero bajo la mesa. Financiamiento y gasto ilegal de las campañas políticas en México, México, Grijalbo, 2018; Martha Gloria Morales y Luis Alberto Fernández (coords.), La elección presidencial de México, 2012. Miradas divergentes, México, Fontamara, 2012.

${ }^{3}$ Rogelio Hernández, "El refugio del PRI durante la alternancia panista”, Foro Internacional, 55 (2015), pp. 45-82.

${ }^{4}$ Instituto Federal Electoral, Secretaría Ejecutiva, "Cifras relevantes del proceso electoral 2011-2012”, México, 28 de junio de 2012. 
Seis años más tarde, y a nivel nacional, la derrota de EPN y su partido resultó espectacular. Su candidato presidencial, el exsecretario de Hacienda, de Energía, de Relaciones Exteriores y de Desarrollo Social, José Antonio Meade, pese a que contó con el apoyo total del gobierno y el esfuerzo de la maquinaria priista por movilizar votos con incentivos materiales, apenas si logró acreditar el $16.4 \%$ de los sufragios. ${ }^{5}$ La izquierda, encabezada por tercera vez por AMLO, obtuvo la victoria con el $53 \%$ de los votos. Esa derrota significó para el PRI no sólo volver a dejar la presidencia, sino resignarse a tener una presencia marginal en el congreso federal. En la Cámara de Diputados, la coalición encabezada por el Movimiento Regeneración Nacional (Morena) obtuvo 307 de los 500 escaños en disputa, en tanto que la encabezada por el PRI sólo logró 62. En un Senado de 128 curules, las logradas por el priismo fueron apenas 13 .

No ha sido México el único caso en que un partido autoritario, tras perder el poder, lo recuperara por vía de las urnas. Un fenómeno similar había ocurrido ya en Taiwán, cuando el Kuomintang (KMT) -partido fundado en 1911 en la China continental y que de 1945 a 1987 gobernó esa isla como partido único- también perdió en las urnas un poder obtenido originalmente por la fuerza. Y si bien en 2008 el KMT retornó al palacio presidencial por voluntad ciudadana, en 2016 volvió a salir de ahí al perder en un proceso no muy diferente del mexicano.

Tras doce años fuera de Los Pinos, el PRI retornó a "su casa” en 2012, pero en un entorno ya muy diferente, pues si

${ }^{5}$ Véase, al respecto, Rogelio Gómez Hermosillo, "Lucro político con la pobreza: las prácticas de compra y coacción del voto en las elecciones de 2018", en Bernardo Barranco, AMLO y la tierra prometida. Análisis del proceso electoral de 2018 y lo que viene, México, Grijalbo, 2018, pp. 81-98. En este trabajo, y a través de encuestas, se encontró que en 2018 el $33.5 \%$ de los electores recibieron algún tipo de oferta que buscaba influir en su voto; la mitad de los que recibieron el ofrecimiento dijo haberlo rechazado, pero de aquellos que lo aceptaron, el $79 \%$ aseguró no tener problema en votar por un partido diferente al que le ofreció algo a cambio del voto. 
bien subsistían prácticas del pasado -financiamiento partidista ilegal, autoridades parciales y corrupción endémica-, ${ }^{6}$ las raíces del pluripartidismo se habían fortalecido. Había ya una oposición activa y una ciudadanía más participativa y consciente de su fuerza, y que disponía de fuentes plurales de información.

Los cambios en el entorno resultaron difíciles de controlar para un partido que, como el PRI, no había nacido para competir por el poder en las urnas, sino para ejercer y administrar un poder previamente adquirido por un proceso revolucionario y asegurado por la vía autoritaria. ${ }^{7}$ En contraste, en 2018, una sociedad cada vez más demandante y con menor tolerancia a la corrupción y la ineficiencia protagonizó algo que puede caracterizarse como una insurgencia electoral -no la primera, pero sí la más efectiva- que en julio se volcó a favor de la opción de izquierda, en parte para apoyar un proyecto nuevo y en parte como un rechazo a quienes habían ejercido el poder. Bajo la conducción de EPN, el partido en el gobierno consumió sus últimas reservas de capital político y, al final, se vio obligado a aceptar una derrota contundente. En vísperas de esas elecciones, EPN apenas si mantenía una aprobación del $21 \% 8$ y el candidato por él designado -ique debió presentarse a la contienda como un tecnócrata sin filiación partidista!- quedó en un lejano tercer lugar. ${ }^{9}$ Más de uno de sus dirigentes expre-

${ }^{6}$ Juan Carlos Mondragón Quintana, Financiamiento de partidos, rendición de cuentas y corrupción en México, México, FLAcso, 2014.

${ }^{7}$ Lorenzo Meyer, Rafael Segovia y Alejandra Lajous, Historia de la Revolución mexicana, periodo 1928-1934. Los inicios de la institucionalización: la política del maximato, vol. 12, México, El Colegio de México, 1978.

${ }^{8}$ Rolando Ramos, "Impacta el periodo electoral en la aprobación del presidente", ElEconomista, 1 de marzo de 2018, https:/ / www.eleconomista. com.mx/politica/Impacta-el-periodo-electoral-en-la-aprobacion-del-presi dente-20180301-0153.html

9 "Da a conocer INE resultados del cómputo de la elección presidencial 2018" (comunicado de prensa núm. 405), México, Central Electoral, Instituto Nacional Electoral, INE, https:/ / centralelectoral.ine.mx/2018/07/06/ da-conocer-ine-resultados-del-computo-de-la-eleccion-presidencial-2018/ 
só el temor de que su instituto dejara de ser políticamente relevante. ${ }^{10}$

En su inicio, el hundimiento con el que concluyó el gobierno de EPN no se vislumbró siquiera como posibilidad. El flamante presidente aseguró que su partido se había puesto al día para ser compatible con la modernidad del país. Y es que por primera vez ese partido había sido capaz de alcanzar la victoria electoral por sí mismo y desde la oposición, es decir, sin contar con el tradicional respaldo del gobierno federal. Además, pudo acreditar un margen de triunfo con credibilidad, muy diferente de victorias absolutamente extraordinarias, como la de 1976, cuando el candidato priista recibió el $100 \%$ de los votos válidos, o la muy competida de 1988, pero en la que el fraude resultó ser el punto contencioso central. ${ }^{11}$

Al último candidato presidencial priista ganador, anterior a la derrota del año 2000 -Ernesto Zedillo en 1994-, se le adjudicó el $48.7 \%$ de la votación, pero en 2012 el exgobernador del Estado de México recibió su constancia de triunfador con el respaldo de sólo poco más de un tercio de los votantes, $(38.2 \%)$. Y aunque la autoridad dio por válido su triunfo, los medios dejaron constancia de que esa cifra quizá hubiera sido menor sin el componente de compra del voto. ${ }^{12}$

La restauración priista fue resultado de múltiples factores, pero no es aventurado suponer que una muy importante -justo como sucedió con el retorno ya comentado del KMT en Taiwán- tuvo que ver tanto con el proyecto priista como con el fracaso del partido en el poder en los dos últimos pe-

${ }^{10}$ Proceso, 22 de julio de 2018.

${ }^{11}$ Julio Labastida Martín del Campo y Miguel Armando López Leyva, "México: una transición prolongada (1988-1996/97)", Revista Mexicana de Sociología, 66 (2004), pp. 761-762.

${ }^{12}$ Según un informe preliminar, que finalmente no tuvo consecuencias legales, de la comisión de investigación del caso de las tarjetas Monex y de otras instituciones financieras, de la Cámara de Diputados, el monto de las tarjetas repartidas por el PRI en vísperas de la elección de 2012, sobrepasó en 13 veces el gasto que le era permitido a su candidato por la ley. Aristegui Noticias, 12 de marzo de 2014. 
riodos presidenciales: el PAN. En 2000, los panistas se habían encontrado finalmente con el éxito en un histórico "asalto" democrático a la vieja fortaleza autoritaria priista. ${ }^{13} \mathrm{Sin}$ embargo, el refrendo de ese triunfo en el 2006 fue con un margen menor al $1 \%$ y bajo fuerte sospecha, ${ }^{14}$ un crecimiento mediocre de la economía -poco más de $2 \%$ anual pese a los altos precios del petróleo exportado- y corrupción, ${ }^{15}$ además de la militarización de la lucha contra las organizaciones del narcotráfico, ${ }^{16}$ y el aumento exponencial de la violencia -en ese sexenio se abrieron más de 102000 carpetas de investigación por homicidio doloso, desapariciones y violaciones de los derechos humanos-, sin que se lograra el objetivo: quebrarle el espinazo al crimen organizado.

Las elecciones intermedias de 2015 se desarrollaron sin sorpresas, pero con un ligero retroceso para el partido del gobierno. En la renovación de la Cámara de Diputados, el PRI recibió el $30.69 \%$ de los sufragios, aunque ganó cinco de las nueve gubernaturas en juego. Sin embargo, al año siguiente, el partido del presidente perdió siete de doce elecciones estatales y los medios ya calificaron ese resultado como "derrota histórica”, tanto para el PRI como para EPN. ${ }^{17}$ Particularmente significativas fueron las derrotas en Veracruz, Tamaulipas, Durango y Quintana Roo, plazas que desde la fundación misma del partido habían permanecido en manos priistas.

${ }^{13}$ El entusiasmo panista por su hazaña electoral en el año 2000 y su significado histórico como la transición a la democracia está bien captado en la obra de Guillermo H. Cantú, Asalto a palacio. Las entrañas de una guerra, México, Grijalbo, 2001.

${ }^{14}$ José Antonio Crespo, 2006: hablan las actas. Las debilidades de la autoridad electoral mexicana, México, Random House Mondadori, 2008.

${ }^{15}$ En torno a la corrupción en el periodo panista, sirve de ejemplo la gestión de Pemex durante las administraciones panistas; véase, como caso de estudio, Ana Lilia Pérez, Camisas azules, manos negras: el saqueo de Pemex desde Los Pinos, México, Grijalbo Mondadori, 2010.

${ }^{16}$ Guillermo Pereyra, "México: violencia criminal y 'guerra contra el narcotráfico””, Revista Mexicana de Sociología, 74 (2012), pp. 429-460.

17 Animal Político, 7 de julio de 2016. 
El revés de 2016 llevó a que uno de sus líderes más influyentes y representativos de los cuadros "tradicionales", el senador Manlio Fabio Beltrones, dejara la dirección del partido y fuera sustituido por un personaje de menor relevancia interna, pero de todas las confianzas del presidente: Enrique Ochoa Reza, hasta entonces al frente de la Comisión Federal de Electricidad. En las tres elecciones locales celebradas en 2017, el PRI pareció recuperarse, pues si bien perdió Nayarit, pudo, en cambio, mantener el Estado de México y Coahuila. Sin embargo, ambas victorias se lograron a un alto costo: se alcanzaron teniendo que incurrir en irregularidades puestas en evidencia por los medios y no generaron la legitimidad esperada, pese a los grandes recursos invertidos y al desgaste de los institutos electorales locales. Al final, los resultados subrayaron más las debilidades que las fortalezas del PRI y de la presidencia. A juicio de observadores participantes, lo ocurrido en esos dos estados terminó por constituir un par de victorias pírricas. ${ }^{18}$

Los triunfos sin credibilidad y las abiertas derrotas del partido del gobierno en 2016 y 2017 fueron, en buena medida, resultado de una reacción a los casos de corrupción mayúscula en la administración federal y entre los "nuevos priistas" en los gobiernos de Veracruz, Chihuahua o Quintana Roo, ${ }^{19} \mathrm{y}$ a la creciente ola de violencia y al clima de inseguridad. Hubo, adicionalmente, otro factor muy importante: el surgimiento de una alternativa al bipartidismo PRI-PAN que funcionaba en México desde finales del siglo anterior.

Desde 2014 empezó a operar en México un nuevo actor partidista de izquierda, el Movimiento Regeneración Nacional, encabezado por el persistente y carismático AMLO. ${ }^{20}$ Este partido-movimiento se propuso ocupar el espacio que estaba

18 Bernardo Barranco (coord.), El infierno electoral. El fraude en el Estado de México y las próximas elecciones de 2018, México, Grijalbo, 2018.

${ }^{19}$ Jenaro Villamil, Cleptocracia. El nuevo modelo de corrupción, México, Grijalbo, 2018.

${ }^{20}$ Héctor Alejandro Quintanar, Las raices del Movimiento Regeneración Nacional, México, Itaca, 2017. 
dejando un PRD cada vez menos combativo, más cercano al gobierno y más dividido. Morena se lanzó tanto contra la izquierda colaboracionista -el perredismo- como contra la derecha, es decir, el PAN y el PRI, a los que caracterizó como dos caras de una misma oferta: "el PRIAN". ${ }^{21}$

Los comicios de 2017 en el Estado de México constituyeron el preámbulo de la elección presidencial de 2018. Y lo que mostró esa votación en el corazón geográfico del peñanietismo fue que, pese a la intervención del gobierno federal en su favor y a los dados cargados que jugaron las instituciones electorales locales, ${ }^{22}$ el PRI, por sí mismo, ya no pudo superar a Morena. Al final, el priista Alfredo del Mazo -hijo y nieto de gobernadores- fue declarado ganador gracias al margen de $2.78 \%$ de votos que le dieron sus aliados: el Partido Verde Ecologista de México (PVEM), el Partido Encuentro Social (PES) y Nueva Alianza (Panal). Si en ese entorno político particularmente favorable para el partido del gobierno, Morena lo alcanzó, entonces se hizo evidente la posibilidad de que la nueva fuerza de izquierda pudiera superar a nivel nacional a la maquinaria priista.

La elección presidencial de 2018 resultó espectacular. Para empezar, por su magnitud. No sólo estaban en disputa la presidencia de la República y los escaños de las cámaras federales de Diputados (500) y Senadores (128), sino también centenares de cargos locales en treinta estados: 3326 posiciones en total. Para EPN y el PRI, lo que estaba en juego era reafirmar su posición como el partido-eje histórico del sistema político mexicano. Para el PAN, lo importante era que sus victorias locales de 2016 desembocaran en la recuperación de la presidencia. Para el PRD, lo prioritario era sobrevivir. Finalmente, para Morena y su líder, la meta inmediata era consolidarse y para ello tenían que romper el círculo de hierro de la

21 AMLO empleó con frecuencia el concepto de PRIAN; véase, por ejemplo, Andrés Manuel López Obrador, Neoporfirismo, hoy como ayer, México, Grijalbo, 2014, p. 387.

22 B. Barranco, op. cit. 
partidocracia PRI-PAN-PRD que durante treinta años había dominado el panorama político nacional. Para el morenismo, sólo desbaratando ese círculo se podría lograr modificar la forma y el contenido del sistema político mismo, es decir, cambiar el régimen.

Desde finales de 2017, las encuestas empezaron a arrojar cifras que colocaban en la delantera a AMLO. ${ }^{23}$ Una atmósfera de alarma se hizo evidente en los círculos de gobierno, empresariales y de la derecha en general. La designación de un tecnócrata sin militancia partidista como candidato del PRI, el secretario de Hacienda, José Antonio Meade, no encendió gran entusiasmo público, pese a que se destacaron su formación académica, su experiencia por haber formado parte tanto de gabinetes del PAN como del PRI -lo que también garantizaba la continuidad-y, sobre todo, el no estar bajo sospecha de corrupción personal. En el PAN, la candidatura fue muy disputada y finalmente recayó en el jefe del partido: Ricardo Anaya, un joven abogado y politólogo mexiquense de talante agresivo, militante del partido desde los 21 años e identificado con la modernidad administrativa. Sin embargo, durante la lucha interna por la candidatura, Anaya dividió profundamente al PAN e hizo eje de su campaña el compromiso de llevar a juicio, por corrupto, al propio presidente de la República. El resultado fue un contrataque desde el gobierno que logró tender un velo de sospecha sobre la probidad del panista al acusarlo de negocios inmobiliarios poco claros en Querétaro.

Si por un largo tiempo los acuerdos explícitos e implícitos entre el PRI y el PAN funcionaron, para 2018 la continuidad de esa cooperación en lo esencial quedó descartada por las dirigencias de ambas organizaciones políticas. La división

${ }^{23}$ En un promedio de sondeos de opinión, en noviembre de 2017, AMLo tenía una ventaja de 11 puntos sobre quien le seguía, el candidato del PRI. Esa ventaja se redujo en febrero de 2018, pero en marzo volvió a subir y para mediados de junio de 2018 se había doblado a poco más de 22 puntos sobre el rival más cercano, esta vez el candidato del PAN. El País, 26 de junio de 2018. 
entre ellas se ahondó a lo largo de la campaña. Anaya superó a Meade en los sondeos de opinión, pero no logró cerrar la brecha frente a AMLO. Las fuerzas de derecha, en particular los empresarios, jugaron con la idea del "voto útil": hacer declinar a Meade y consolidar un gran frente anti-AMLO en torno a Anaya. El intento se hizo pero no cuajó, entre otras razones, porque el presidente, único actor que podía eliminar al candidato del PRI de la contienda, no lo aceptó. Desde su perspectiva, si alguien debía declinar era su acusador: Anaya.

Fue así como se llegó a un 1 de julio en el que 56.5 millones de ciudadanos salieron a votar (63.4\% del padrón) y AMLo recibió el 53.19\% de los sufragios; Anaya, el 22.27\%, y Meade, sólo el 16.40\%. La victoria del candidato de izquierda fue reforzada por el hecho de que su partido, Morena, también se alzó con la victoria en el poder legislativo federal y en un buen número de congresos estatales. ${ }^{24}$ Por primera vez en su historia, el PRI quedó como una fuerza relativamente marginal, tanto a nivel nacional como local. El peñanietismo se hundió y en el proceso arrastró a su partido.

\section{El PEÑANieTiSMo, TEORÍA Y PRÁCTICA}

La primera gran acción política de EPN como presidente fue realmente espectacular. El 2 de diciembre, un día después de asumir su puesto, anunció que las principales fuerzas políticas representadas en el Congreso pondrían sus firmas junto a la suya en un Pacto por México (PPM). Fue un golpe maestro. Dentro y fuera de México se difundió la imagen del joven presidente rodeado por los dirigentes del PRI, PAN y PRD en el Castillo de Chapultepec cuando, solemnemente, signaban ese documento. ${ }^{25} \mathrm{El}$ mensaje fue claro: los adversarios electo-

24 "Da a conocer INE resultados del cómputo de la elección presidencial 2018", art. cit.

${ }^{25} \mathrm{El}$ documento completo puede consultarse en: "Texto completo del Pacto por México", Animal Político, 3 de diciembre de 2012, https://www. animalpolitico.com/2012/12/los-cinco-acuerdos-del-pacto-por-mexico/ 
rales habían sido invitados por un vencedor generoso y negociador para ser acompañantes de un proyecto que buscaba acelerar la transformación de México por la ruta que se había tomado desde los ochenta, el neoliberalismo económico. A inicios de 2014, la revista Time dedicaría una portada a EPN con este encabezado: "Saving Mexico. How Enrique Peña Nieto's sweeping reforms have changed the narrative in his narcostained nation". 26

En la cúpula partidocrática no hubo ya una voz abiertamente disidente y con autoridad para hacer contrapeso a la posición presidencial. Para entonces, AMLO ya había roto con el PRD y empezado a construir una nueva fuerza de oposición real. Por eso, en vísperas de iniciarse el nuevo gobierno, en septiembre y octubre de 2012 y ya sin la presencia de AMLO, fueron los dirigentes perredistas quienes propusieron y negociaron con los representantes de EPN, primero, y con los dirigentes panistas, después, la posibilidad de llegar un gran acuerdo, a un pacto que desembocara en algo parecido a un gobierno de coalición. ${ }^{27} \mathrm{El}$ grupo de EPN compró la idea y fue así como nació el Pacto por México, PPM.

Ya negociado, el PPM se presentó como un compromiso entre adversarios pero no enemigos, que tras superar sus naturales diferencias buscaron los puntos de encuentro que les permitieran lograr tres grandes metas: el fortalecimiento del Estado, la democratización de la economía y de la política, y la ampliación y concreción de los derechos sociales. Los tres objetivos fueron definidos de tal manera que, en teoría, no entraran en conflicto con los supuestos principios ideológicos de ninguno de los partidos firmantes. Para lograrlo, definieron cinco ejes temáticos: 1) la sociedad de derechos y libertades; 2) el crecimiento de la economía, el empleo y la competitividad; 3 ) la seguridad y la justicia; 4) la transparencia, la rendición de cuentas y el combate a la corrupción, y

${ }^{26}$ Michael Crowley, “Saving Mexico. How Enrique Peña Nieto's sweeping reforms have changed the narrative in his narco-stained nation", Time, 24 de febrero de 2014.

${ }^{27}$ Excélsior, 9 de junio de 2013. 
5) la gobernabilidad democrática. Para darle contenido a esos grandes temas, redactaron 95 compromisos puntuales, advirtiendo que su logro no debía ni podía ser tarea exclusiva de las dirigencias políticas, sino que requería de la participación ciudadana en su diseño, ejecución y evaluación.

En la práctica, la participación ciudadana, si la hubo, no se notó. El PPM finalmente no se tradujo en una mejoría de las percepciones de los trabajadores, ni en un combate efectivo a la corrupción, tampoco en la recuperación de la seguridad, ni en confianza en el sistema judicial ni en la instauración de una gobernabilidad democrática. A finales de 2018, la confianza ciudadana en las instituciones públicas, con la salvedad del ejército, era baja ${ }^{28}$ y la aprobación del autor del PPM, el presidente, era de apenas el 20\%.29

El corazón del Pacto fue, a fin de cuentas, un puñado de "reformas estructurales". ${ }^{30} \mathrm{Y}$ de éstas, la principal, por su concreción y el monto de los recursos en juego, fue la energética. Con el apoyo de las bancadas del PAN y del PRD en el Congreso y con el aplauso casi unánime del sector privado nacional y extranjero, en diciembre de 2013, el presidente logró que se modificara la Constitución y se hiciera a un lado lo que por mucho tiempo se había calificado como uno de los mayores logros del nacionalismo de la Revolución mexicana: reservar para el Estado y su gran empresa, Petróleos Mexicanos (Pemex), la propiedad, la exploración, la explotación, la refinación, el transporte y la comercialización de los hidrocarburos, por así convenir al interés nacional. ${ }^{31}$

28 Consulta Mitofsky, "Confianza en las instituciones, 2018”, octubre de 2018.

29 Consulta Mitofsky, "Evaluación 23 trimestres de gobierno de Enrique Peña Nieto", 11 de noviembre de 2018.

30 Senado de la República, Balance de las reformas estructurales [4 tomos], México, Instituto Belisario Domínguez / Senado de la República, LXIV Legislatura, 2018.

${ }^{31}$ Gobierno de la República, Reforma energética, https:/ /www.gob.mx/ cms/uploads/attachment/file/10233/Explicacion_ampliada_de_la_Re forma_Energetica1.pdf 
Desde el sexenio de Miguel Alemán (1946-1952), la presidencia había intentado reintroducir el capital privado extranjero al campo de los hidrocarburos. Al suscribir contratos-riesgo, primero, con empresas extranjeras y, más adelante, al dividir el campo de la petroquímica en primaria y secundaria, en la que ya se admitió a la iniciativa privada, sucesivos gobiernos fueron ampliando paulatinamente el área de lo privado en la explotación del petróleo. De todas formas, al suscribirse en 1993 el acuerdo internacional que redefinió la naturaleza misma del modelo económico mexicano, el Tratado de Libre Comercio de la América del Norte (TLCAN), el gobierno de Carlos Salinas se cuidó de no meter aún en ese saco el petróleo. Eso no significó que se detuviera el paulatino abandono de Pemex como la empresa estatal indispensable e insustituible, ni que dejaran de ampliarse los rubros en que podían entrar los capitales privados en materia de energía. El gobierno de Felipe Calderón pretendió concesionar la perforación en aguas profundas -donde, se dijo, residía la nueva frontera petrolera mexicana- a empresas privadas, pero la oposición en el Congreso se lo impidió. Finalmente, ya con el PRI de nuevo en el timón y el PPM como carta de navegación, EPN llevó a su conclusión lógica la reforma energética, sin importar que una mayoría ciudadana no apoyara esa franca apertura a la inversión privada en hidrocarburos. ${ }^{32}$

El 20 de diciembre de 2013, una enmienda constitucional dio el banderazo de salida para acabar con los monopolios estatales en materia de petróleo y electricidad. La idea central, se aseguró, era mantener a Pemex y a la Comisión Federal de Electricidad (CFE) como "empresas productivas del Estado", pero abrir todo el campo energético al capital privado -nacional y externo- para, mediante inversión masiva y amplia competencia, descubrir y explotar

32 De acuerdo con una encuesta publicada por el Pew Research Center, de Washington, el 59\% de la muestra se oponía a la presencia de capital externo en Pemex y sólo el $34 \%$ apoyaba la posibilidad; véase Pew Research Center, "Mexican President Peña Nieto's Ratings Slip with Economic Reform”, Global Attitudes Survey, Q.44, primavera de 2014. 
nuevos yacimientos de hidrocarburos en circunstancias en que la producción local iba a la baja y la demanda interna, al alza.

Una vez abierto el petróleo a la lógica del mercado, se iniciaron las licitaciones y para 2017 se habían firmado más de un centenar de contratos en los que participaron más de setenta empresas privadas mexicanas y extranjeras. Se anunció entonces que el valor de las inversiones comprometidas podría llegar a más de 160000 millones de dólares. ${ }^{33}$ Sin embargo, el gobierno de EPN concluyó sin poder mostrar las bondades prometidas por la reforma: aumento de la producción y mejores precios. Para el mexicano promedio, lo tangible fueron las bajas en la producción y los aumentos en el costo del combustible y la electricidad, la dependencia creciente del gas y la gasolina importados, y los escándalos sobre la mala administración y la corrupción en Pemex, más un inaudito robo de combustible en los ductos de la empresa por el crimen organizado. ${ }^{34}$ En una encuesta levantada el mismo día de la elección de 2018, el 59\% de los consultados respondieron que la reforma energética era perjudicial y sólo el 10\% la consideró benéfica. En relación al futuro, el $28 \%$ se declaró en favor de cancelar la reforma, el 56\% deseaba que se revisara y apenas $13 \%$ aceptó que quedara como estaba. ${ }^{35}$

Para el ocaso del sexenio, México importaba el $78 \%$ de las gasolinas que consumía y la producción de Pemex había caído al punto de que, a partir de octubre de 2018, la empresa importaba crudo ligero para surtir sus propias refinerías que, en cualquier caso, hacía tiempo que no operaban a plenitud y cubrían sólo un tercio de la demanda. ${ }^{36}$

La otra reforma muy controvertida y generadora de conflictos sociales fue la educativa, aprobada en diciembre de 2012, promulgada en el febrero siguiente y que para sep-

33 Forbes México, 25 de abril de 2018.

34 Ana Lilia Pérez Mendoza, Pemex RIP. Vida y asesinato de la principal empresa mexicana, México, Grijalbo, 2017.

35 Milenio, 2 de agosto de 2018.

${ }^{36}$ El Economista, 27 de agosto de 2018. 
tiembre ya tenía diseñado todo su marco legal y estaba en marcha.

La prueba del Plan Nacional para la Evaluación de los Aprendizajes (PLANEA) de 2015 mostró que elevar la calidad de la educación mexicana era indispensable y urgente. ${ }^{37}$ Sin embargo, el impulso reformista del gobierno en este rubro enfrentaría resistencias rápidamente, al dar prioridad a la implantación de un sistema de evaluación de los docentes y toparse ahí con la casi inevitable oposición de la disidencia sindical.

En una maniobra que recordaba a otras del pasado, el 26 de febrero de 2013, las autoridades detuvieron a la líder vitalicia del Sindicato Nacional de Trabajadores de la Educación (sNTE), Elba Esther Gordillo, la acusaron de delitos financieros por 2000 millones de pesos, la enviaron a prisión cinco años y propiciaron el ascenso de una nueva directiva encabezada por Juan Díaz de la Torre, comprometida a dar su apoyo a la reforma emprendida por el gobierno. Un lustro después, los cargos se diluyeron y la maestra Gordillo pudo salir de prisión. Ya en libertad, la dirigente se dijo dispuesta a recuperar su posición en el SNTE y a luchar contra la reforma educativa. Pero no era ella la única enemiga de la reforma; lo era, sobre todo, el ala sindical disidente del movimiento magisterial, la Coordinadora Nacional de Trabaja-

37 En la prueba Planea de 2015, sólo el 3.1\% de los alumnos de secundaria quedaron en el nivel más alto en matemáticas y el $6.1 \%$ en lenguaje y comunicación. Resultados nacionales 2015, Lenguaje y Comunicación, México, Instituto Nacional para la Evaluación de la Educación, INEE, 2015, http://planea.sep.gob.mx/content/general/docs/2015/Planea Fas ciculo_9.pdf

En la prueba del Programa para la Evaluación Internacional de Alumnos (PISA) de ese mismo año, México quedó por debajo del promedio de los países en que se aplicó. Menos del 1\% de los evaluados mexicanos alcanzó el nivel de excelencia en las tres áreas valoradas: ciencias, matemáticas y lectura; ocDE, "Nota país. Programa para la Evaluación Internacional de Alumnos, PISA, 2015. México”, https://www.oecd.org/ pisa/PISA-2015-Mexico-ESP.pdf 
dores de la Educación (CNTE) y el movimiento de oposición encabezado por AMLo.

La parte de la reforma educativa que primero se puso en marcha fue el mecanismo de evaluación de los docentes, que en la práctica quitaba al poderoso gremio magisterial -1619990 miembros, según cifras del Sindicato Nacional de Trabajadores de la Educación, SNTE- ${ }^{38}$ el control del reclutamiento y promoción de los docentes, asumiendo que la corrupción propiciada por ese control incidía directamente en la mala calidad de la enseñanza.

La creación de un servicio profesional docente y el ingreso al mismo mediante exámenes a cargo del Instituto Nacional para la Evaluación de la Educación (INEE) se propuso como la vía para llegar a dar forma a una estructura meritocrática que ya no supeditara la carrera magisterial a la lógica sindical. ${ }^{39}$ La evaluación de los maestros se inició en medio de resistencias, pero no se detuvo. El sistema estaba aún afinándose cuando el sexenio de EPN llegó su final. Se calculó que al cierre de 2018 se habría evaluado a 1789000 educadores.

Los intereses creados alrededor del sistema de la educación pública resultaron ser obstáculos formidables. Los críticos y enemigos de la reforma -que la calificaron de laboral y punitiva más que educativa- ${ }^{40}$ sostuvieron que la idea de someter a exámenes uniformes a docentes que se habían formado y desarrollado en entornos tan disímbolos como la capital del país o la montaña de Guerrero ponía en desventaja a quienes se encontraban en las zonas más pobres o

38 "Revela SNTE su membresía", Reforma, 15 de mayo de 2017, citado por Mexicanos Primero, "Noticias de Hoy. Revela SNTE su membresía", http://mexicanosprimero.org/index.php/educacion-en-mexico/enterate/noticias-de-hoy/4289-revela-snte-su-membresia

${ }^{39}$ Gobierno de la República, Reforma educativa. Resumen ejecutivo,www. gob.mx/cms/uploads/attachment/file/2924/Resumen_Ejecutivo_de_ la_Reforma_Educativa.pdf

${ }^{40}$ Hugo Aboites, "INEE y cancelación de la reforma educativa", $L a$ Jornada, 21 de julio de 2018. 
aisladas frente a los que laboraban en entornos más prósperos y comunicados. Desde esta perspectiva, debería primero de dotarse de mejores medios y condiciones a los maestros más rezagados y sólo después proceder a su evaluación.

Fue la cNTE la que opuso mayor resistencia a los cambios diseñados por la Secretaría de Educación Pública (SEP), encabezada por Aurelio Nuño, un personaje importante del círculo presidencial. El conflicto desembocó en choques violentos que culminaron con el de Nochistlán, en Oaxaca, donde un enfrentamiento entre disidentes y autoridades se saldó con al menos seis muertos y más de un centenar de heridos. ${ }^{41}$

Al final, la movilización de los inconformes y el rechazo de Morena a la reforma llevó a un impasse. Tras el triunfo electoral de AmLo y el dominio de Morena en el Congreso, los nuevos responsables del ramo anunciaron que se echarían abajo los cambios emprendidos en este campo por EPN y que en su lugar se pondría en marcha una transformación no punitiva del magisterio. Al final, la reforma educativa peñanietista simplemente no se concretó.

$\mathrm{Al}$ inicio de 2018, la Auditoría Superior de la Federación (ASF) constató que hasta 2016 la calidad de la educación mexicana no había mejorado. La SEP argumentó que los resultados de su esfuerzo en este campo no podían verse de inmediato y que mejorarían en los ciclos escolares de 2018 a 2019. ${ }^{42}$ Que un cambio de fondo en el modelo educativo mexicano era urgente, nadie lo negaba, el problema estaba en los profundos desacuerdos políticos sobre cómo llevarlo a cabo.

La reforma a la Ley Federal del Trabajo quedó lista para ponerse en marcha al final del gobierno de Felipe Calderón, pero fue en la administración de EPN que se hizo efectiva. La idea central del cambio en esta materia era poner a tono con

41 Animal político, 20 de junio de 2016.

42 Nayeli Roldán, "Reforma Educativa no ha mejorado la educación, dice Auditoría; SEP acepta retrasos pero resalta mejoras", Animal Político, 22 de febrero de 2018, https://www.animalpolitico.com/2018/02/refor ma-educativa-no-mejoro-escuelas/ 
la época de gran movilidad de la mano de obra una legislación que conservaba mucho de la protección al trabajador sindicalizado propia del anterior modelo del desarrollo económico proteccionista y corporativo, que había dado estabilidad en el pasado, pero que, según sus promotores, para el siglo Xxi se había convertido en un serio obstáculo para la dinámica de un mercado laboral que, en la práctica, tenía carácter mundial y debía regirse por nuevas reglas. ${ }^{43}$

El concepto de "flexibilidad laboral" constituyó el leitmotiv de esta reforma. En términos prácticos, "flexibilidad" significó dar al empleador un mayor campo de libertad para contratar, modificar las condiciones laborales y despedir a los contratados. La legislación también incorporó la subcontratación sin responsabilidad patronal, el contrato por horas, un límite al monto de los salarios caídos y varias otras medidas favorables al patrón en función, y se argumentó no favorecer al capital, sino hacer competitiva la economía mexicana en el mercado mundial y aumentar el empleo. ${ }^{44}$

En términos generales, los sindicatos no opusieron una gran resistencia a los nuevos lineamientos. Al final de su gobierno, EPN anunció que en su sexenio se habían creado 3.7 millones de empleos y que su política laboral debía considerarse exitosa. ${ }^{45}$ Sin embargo, un examen detallado de la calidad de esos empleos ponía en duda la naturaleza de su éxito. Las cifras del Instituto Nacional de Estadística y Geografía (INEGI) sostenían que, en efecto, el desempleo era bajo, pero también que el $34 \%$ de la población ocupada recibía apenas entre uno y dos salarios mínimos, en tanto que aquellos empleados que percibían una remuneración más digna,

43 Para un análisis de todos los temas de la reforma propuesta en 2012 por el calderonismo, puede consultarse Centro de Estudios Sociales y de Opinión Pública, Ley Federal del Trabajo, propuestas de reforma, alcances y opinión pública, México, Cámara de Diputados del Congreso de la Unión, 2012.

${ }^{44}$ Consejo Coordinador Empresarial, "Mensaje extraordinario, aprobación de la reforma laboral", comunicado del 13 de noviembre de 2012.

${ }^{45}$ La Jornada, 13 de agosto de 2018. 
superior a los cinco salarios mínimos, representaban apenas $5.8 \%$ de la masa asalariada. ${ }^{46}$

La reforma en telecomunicaciones y radiodifusión que, en principio, debía disminuir la importancia relativa de las grandes concentraciones en este ramo y propiciar la competencia, tuvo un éxito limitado. Efectivamente, entraron al mercado nuevos actores, pero al final del sexenio, el gobierno refrendó por veinte años más, hasta 2041, las concesiones a las dos grandes televisoras, Televisa y Azteca, que juntas representaban el $95 \%$ de las concesiones de televisión abierta. ${ }^{47}$ Así pues, el carácter duopólico de la televisión siguió sin cambio.

La reforma financiera, promulgada a inicios de 2014, que se suponía facilitaría un crédito más barato a empresas y hogares, tuvo un impacto menor que el anunciado. Para 2018, menos del $30 \%$ de las pequeñas y medianas empresas estaban bancarizadas. ${ }^{48}$ Por otra parte, pese a lo relativamente pequeño de su mercado y al modesto crecimiento del PIB, la banca comercial tuvo beneficios sorprendentes: al final de 2017, su ganancia real fue $20.6 \%$ superior respecto del año anterior, en tanto que el PIB per cápita creció apenas $1.01 \%$. En contraste, la reforma hacendaria sí fue más efectiva, ya que logró más que duplicar la recaudación fiscal, al pasar de un pobre $8 \%$ del PIB, en 2006, al 17\%, en 2017. De todas formas, México seguía estando por debajo del promedio de América Latina en esta materia, pues el porcentaje regional fue del $22.7 \%$.

La reforma del sistema de justicia penal se planteó desde 2008, pero fue en 2016 cuando se puso en marcha. Se trató, efectivamente, de un sistema nuevo, el acusatorio, que sustituyó los juicios escritos por los orales. Esto significó un cambio histórico y sustantivo. En su arranque, el nuevo sistema

46 Forbes México, 6 de abril de 2018.

${ }^{47}$ Judith Mariscal, Estudio sobre el mercado de televisión abierta, México, Telecom / CIDE, 2011, p. 25.

48 http:/ / www.opencap.mx/bancarizacion-en-mexico-2018/ (consulta de noviembre de 2018). 
mostró que, en efecto, los procesos ya eran más ágiles, transparentes y con mejores resultados, aunque la nueva modalidad jurídica iba a requerir de un tiempo largo para llegar a ser plenamente efectiva, especialmente por la falta de personal calificado en las fiscalías y en la policía. ${ }^{49}$

Donde el fracaso del compromiso reformista inicial de EPN resultó mayor y más visible fue en el combate a la corrupción, a la violencia criminal y a la inseguridad. En el primer renglón, ni siquiera se intentó realmente llevar a la práctica el prometido combate a los corruptos. Por lo que hace a la disminución de la violencia desatada por el crimen -el organizado y el común-, la estrategia simplemente se concretó a mantener y continuar con las políticas heredadas del sexenio anterior y, desde luego, se tuvieron los mismos resultados.

$\mathrm{Al}$ arranque de su gobierno, EPN anunció que él y un grupo de políticos relativamente jóvenes que le acompañaban eran la encarnación de un "nuevo PRI". Entre estos supuestos representantes de la renovación, se encontraba un puñado de gobernadores de estados donde este partido se había mantenido ininterrumpidamente en el poder y que habían sido un gran apoyo en la campaña de EPN: Javier Duarte, en Veracruz; César Duarte, en Chihuahua, y Roberto Borge, en Quintana Roo. Para 2017, esa "tercia de ases" eran ya exgobernadores y, también, símbolos de la enorme corrupción del sexenio, pero no eran los únicos. De acuerdo con denuncias penales y con las investigaciones de la ASF, se sospechaba que los 22 gobernadores priistas cuyas administraciones habían coincidido con la de EPN, habían desviado ilegalmente recursos por 259000 millones de pesos. ${ }^{50}$ Una minoría, cinco, habían sido arrestados o tenían orden

${ }^{49}$ World Justice Project, México, "La nueva justicia penal en México. Avances palpables y retos persistentes", worldjusticeproject.mx/wpcon tent/uploads/2018/09/WJPMX-LaNuevaJusticiaPenalMexico_.pdf; Benito Ramírez Martínez, "El 'fracaso' del sistema de justicia penal acusatorio en México", Hechos y Derechos (2017), núm. 40, https://revistas.juridicas. unam.mx/index.php/hechos-y-derechos/article/view/11440/13340

${ }^{50}$ Sin Embargo, 22 de abril de 2017. 
de aprehensión, cuatro más tenían denuncias ante la Procuraduría General de la República (PGR) y el resto se encontraban libres, aunque no enteramente de sospecha.

La imagen misma de EPN quedó tocada por el tema de la corrupción tras un reportaje de noviembre de 2014, elaborado por un grupo de periodistas del equipo de Carmen Aristegui, que dejó al descubierto que una residencia en las Lomas de Chapultepec, en la Ciudad de México, valuada en siete millones de dólares, había sido construida según especificaciones de y para el presidente y su familia por un contratista ligado de tiempo atrás a la obra pública del Estado de México y que, en ese momento, era también parte del grupo que construiría el tren Ciudad de México-Querétaro: Juan Armando Hinojosa Cantú (Grupo Higa). ${ }^{51}$ Tras el reportaje, el proyecto del tren rápido se canceló, pero Aristegui y su grupo perdieron el espacio radiofónico que ocupaban en la empresa Mvs. ${ }^{52}$ Más tarde, una Secretaría de la Función Pública encabezada por un personaje del propio equipo del presidente, Virgilio Andrade, declaró a EPN libre de cualquier conflicto de intereses relacionado con la mansión. Sin embargo, para entonces el llamado "escándalo de la Casa Blanca" había dejado ya una marca indeleble en la legitimidad de EPN y su gobierno. Con anterioridad, el PAN había hecho públicas unas grabaciones que ponían al descubierto el uso puntual de programas federales de la Secretaría de Desarrollo Social (Sedesol) -los de la Cruzada contra el Hambrepara inducir el voto de los veracruzanos a favor del PRI. ${ }^{53} \mathrm{Un}$ ejemplo similar, conocido como la "Estafa Maestra", se puso posteriormente al descubierto; en ese caso, las operaciones involucraron contratos por 7000 millones de pesos y se efectuaron entre secretarías de Estado, universidades públicas y

51 Daniel Lizárraga et al., La casa blanca de Peña Nieto. La historia que cimbró un gobierno, México, Grijalbo, 2015.

${ }^{52}$ Loc. cit.

53 "El PAN acusa al gobierno de Peña de usar recursos con fines políticos", Expansión, 17 de abril de 2013, expansion.mx/nacional/2013/04/17/ el-pan-acusa-al-gobierno-de-pena-de-usar-recursos-con-fines-politicos 
empresas inexistentes para, finalmente, desviar los recursos a las arcas del PRI. ${ }^{54}$ En gran medida fue la percepción pública de una corrupción generalizada y sin castigo el factor que contribuyó a la derrota electoral del partido en el gobierno en julio de 2018.

En medio de una atmósfera pública que demandaba medidas efectivas contra la corrupción -definida oficialmente como "el abuso del poder en beneficio propio"-, en 2014 se propuso la creación de una fiscalía anticorrupción completamente independiente de la presidencia. En mayo de 2015, se publicó en el Diario Oficial de la Federación el decreto que creaba el Sistema Nacional Anticorrupción (sNA). ${ }^{55}$ Sin embargo, pese a lo urgente y serio del tema, y aunque se dio forma a la estructura del sistema, el gobierno de EPN llegó a su final sin que ese fiscal hubiera podido ser nombrado.

La inseguridad y la violencia fueron una de las peores herencias que recibió EPN del sexenio de Felipe Calderón. Las ejecuciones registradas en el sexenio calderonista sumaron 83000 y se calcularon en 25276 los desaparecidos. ${ }^{56}$ Para hacer frente a tamaña ola criminal -en buena medida producto de la lucha entre y contra las organizaciones de narcotraficantes, subproducto de la "guerra contra el narco" del gobierno anterior- se habilitó a la Secretaría de Gobernación (Segob) como una supersecretaría que absorbería las tareas, las fuerzas -en concreto, la PFP- y los recursos de la antigua Secretaría de Seguridad Pública.

El cambio en el organigrama del gobierno federal no logró alterar las inercias. EPN continuó con la estrategia diseñada bajo el calderonismo y Gobernación desempeñó un papel 2018.

${ }^{54}$ Manuel Ureste Cava et al., La estafa maestra, México, Temas de Hoy,

${ }^{55}$ Decreto por el que se reforman, adicionan y derogan diversas disposiciones de la Constitución Política de los Estados Unidos Mexicanos, en materia de combate a la corrupción, Diario Oficial de la Federación, 27 de mayo de 2015.

56 Semanario Zeta, 23 de noviembre de 2012; Proceso, 30 de noviembre de 2012. 
secundario en este campo. El peso de las acciones contra el narcotráfico y otros aspectos del crimen organizado, como el robo en gran escala de combustible de los ductos de Pemex, lo siguieron llevando el Ejército y la Armada. En cualquier caso, la intensidad de estas luchas no amainó. En una estadística hecha pública por el Ejército, se aceptó que entre 2007 y 2016 hubo un promedio de 1.07 encuentros armados diarios entre los efectivos de esa institución y las organizaciones criminales. ${ }^{57}$

El empleo de los recursos humanos y materiales del gobierno con el mismo enfoque en torno al problema de la violencia del sexenio anterior llevó a resultados similares. Siguiendo las propuestas del gobierno estadounidense, las acciones de las autoridades mexicanas se enfocaron en continuar con la captura o eliminación de grandes capos ${ }^{58}$-cuyos casos más notorios fueron el de Joaquín "Chapo" Guzmán, uno de los jefes del llamado Cártel de Sinaloa, y el del Mayo Zambada, fugado y recapturado dos veces, y finalmente deportado y condenado en Estados Unidos-, pero un resultado no contemplado fue la proliferación de organizaciones nuevas o más pequeñas. De entre las nuevas, la más ostensible fue la del Cártel Jalisco Nueva Generación. En lo que se refiere a las organizaciones relativamente pequeñas, muchas expandieron sus actividades a campos distintos de la producción y comercialización de drogas, afectando de forma más directa a la población local: asaltos, robo de combustible, secuestros, cobro de protección, trata de personas y otras. ${ }^{59}$

${ }^{57}$ La Jornada, 13 de mayo de 2017.

${ }^{58}$ Véase, al respecto, la entrevista con el general Michael Hyden, exjefe de la CIA; Dolia Estévez, "Ex director de la CIA: La agencia espía a líderes en México, 'nunca dijimos que se dejaría de hacer' ", Sin Embargo, 1 de noviembre de 2018, https:/ /www.sinembargo.mx/01-11-2018/3490066

${ }^{59} \mathrm{La}$ bibliografía en torno al crimen organizado es numerosa, entre los trabajos recientes, se encuentran los de Luis Astorga, ¿Qué querían que hiciera?, México, Grijalbo, 2015; Carmen Boullosa y Mike Wallace, A Narco History: How the United States and Mexico Jointly Created the Mexican Drug War, Nueva York, or Books, 2015; Guadalupe Correa-Cabrera, Los Zetas inc. 
De acuerdo con el registro del INEGI, entre 2013 y 2018, es decir, en el sexenio de EPN, hubo más de 156000 homicidios en México. ${ }^{60} \mathrm{Al}$ concluir 2018, la intensidad de la violencia no daba señales de amainar, sino todo lo contrario: iba en aumento y la herencia recibida se legaría, de nuevo, al siguiente sexenio.

Ante la incapacidad del Estado para hacer efectivo su papel de protector de la sociedad contra la violencia criminal, en algunas de las regiones más castigadas se expandieron las organizaciones de autodefensa. ${ }^{61}$ Sería en Michoacán donde este fenómeno adquiría mayor relevancia, por la lucha entre las agrupaciones criminales y los productores de bienes agrícolas exportables. ${ }^{62}$ Por las mismas razones, surgieron policías comunitarias, como la creada en 2011 en el municipio michoacano de Cherán, para defender sus bosques del crimen organizado, que se dieron a conocer a nivel nacional e internacional y se mantuvieron activas durante todo el sexenio de EPN. ${ }^{63}$

Para 2013, las organizaciones criminales -la Familia, los Caballeros Templarios, la Resistencia, el Cártel Jalisco Nueva Generación- ya tenían presencia en 54 de los 113 municipios de Michoacán. ${ }^{64}$ Ante la impotencia del gobierno estatal, el federal decidió nombrar en 2014 un responsable de coordinar la acción de las fuerzas locales y federales y reimponer la autoridad en zonas donde ya se había perdido el control te-

Criminal corporations, energy and civil war in Mexico, Austin, University of Texas Press, 2017.

${ }^{60}$ Instituto Nacional de Estadística y Geografía, INEGI, "Datos preliminares revelan que en 2018 se registraron 35 mil 964 homicidios", comunicado de prensa 347/19, https:/ / www.inegi.org.mx/contenidos/saladepren sa/boletines/2019/EstSegPub/homicidios2018.pdf

61 Proceso, 23 de junio de 2012.

62 José Manuel Miles Valverde, Todos somos autodefensas: El despertar de un pueblo dormido, México, Grijalbo, 2017.

63 Véase, al respecto, Linda Pressly, “Cherán, el pueblo de México que expulsó a delincuentes, políticos y policías”, $B B C, 17$ de octubre de 2016, https://www.bbc.com/mundo/noticias-america-latina-37644226

64 Proceso, 3 de noviembre de 2013. 
rritorial. El nombramiento recayó en Alfredo Castillo, exprocurador mexiquense, quien arribó a la entidad en calidad de comisionado para el Desarrollo Integral de Michoacán. Castillo redujo el protagonismo de las autodefensas y disminuyó la capacidad de acción del crimen organizado, pero sin lograr erradicarlo. La violencia desatada por los grupos delincuenciales siguió siendo parte de la vida cotidiana en Michoacán. ${ }^{65}$

Fue en Guerrero donde tuvo lugar el acto violento de mayor impacto político en el sexenio de EPN y lo protagonizó la policía local de Iguala en combinación con el crimen organizado. Sus reverberaciones cruzaron las fronteras de México y afectaron muy negativamente la imagen de EPN y del país. Entre la noche del 26 de septiembre de 2014 y la madrugada del 27, una acción de violencia extrema de los policías municipales de Iguala, supuestamente ordenada por un grupo de narcotraficantes locales llamado Guerreros Unidos, concluyó con un saldo de nueve muertos, 27 heridos y 43 estudiantes de la escuela normal rural Raúl Isidro Burgos, de Ayotzinapa, desaparecidos.

Los asesinatos y la desaparición forzada de los estudiantes no tuvieron la atención inicial del gobierno federal que el hecho merecía. Finalmente, la tuvo como resultado de la movilización de los padres de los estudiantes que, a su vez, detonó una movilización mayor en México y que pronto tuvo réplicas en el exterior hasta llegar a los organismos internacionales y constituir un elemento en la campaña electoral de $2018 .{ }^{66}$

En un inicio, el gobierno y, directamente, el presidente pretendieron minimizar el asunto al tratarlo como una desaparición más en un país con miles de desaparecidos (oficialmente, para 2018 se tenía registro de 30485 personas desaparecidas). ${ }^{67}$ Sin embargo, como respuesta a las movilizaciones, la PGR arrestó a casi un centenar de personas -tan-

${ }^{65}$ José Gil Olmos, Las batallas de Michoacán, México, Ediciones Proceso, 2015.

${ }^{66}$ Anabel Hernández, La verdadera noche de Iguala: la historia que el gobierno trató de ocultar, México, Grijalbo, 2016.

${ }^{67}$ El País, 9 de octubre de 2018. 
to policías como presuntos delincuentes, además del alcalde de Iguala y a su esposa- y en enero de 2015 presentó un informe que se conoció como "la verdad histórica". Ahí se asentó que, por un error, el grupo delictivo que controla la zona de Iguala y, por ende, el cultivo de amapola y el trasiego de opio, confundió la toma de varios autobuses por los estudiantes -que pretendían utilizarlos para ir a la Ciudad de México y ser parte de la conmemoración de la matanza de estudiantes de 1968- con una operación de un grupo rival, los Rojos, para apoderarse de un cargamento de cocaína, y ordenaron a la policía local, que estaba a su servicio, detener la maniobra a como diera lugar, capturar a los normalistas, ejecutarlos, incinerarlos y arrojar sus restos a un río cercano. ${ }^{68} \mathrm{Al}$ final, esa explicación fue rechazada por los familiares de las víctimas y puesta en duda por un grupo internacional de expertos forenses. Un punto crucial en la controversia entre autoridades y familiares de los estudiantes fue que no se permitió a los investigadores entrar a las instalaciones, en Iguala, del 27 Batallón de Infantería del Ejército ni someter a interrogatorio a los mandos del batallón, no obstante que esa corporación tenía encomendadas tareas de inteligencia en la zona y varios militares fueron testigos directos de, al menos, la parte inicial del drama.

EPN llegó al fin de su sexenio sin haber podido hacer creíble la explicación oficial sobre la tragedia de Ayotzinapa y el nuevo gobierno debió comprometerse, desde antes de asumir el poder, a reabrir todo el expediente, rehacer la investigación y no concluirla hasta dejar satisfechos con el resultado a los familiares y a la opinión pública nacional e internacional.

El desastre político en que se convirtió el caso de los normalistas de Ayotzinapa, junto al escándalo de la "Casa Blanca”, la impúdica corrupción de gobernadores cercanos al presidente y una violencia e inseguridad que mostraron la incapacidad de todo el aparato de seguridad del Estado para contenerlas, se convirtieron en símbolos de la naturaleza del

${ }^{68}$ La Jornada, 28 de enero de 2015; Excélsior, 28 de enero de 2015. 
gobierno encabezado por EPN, pero también, y sobre todo, del régimen, del que ese gobierno era el último eslabón de una cadena que tenía su origen y ancla en la consolidación de la Revolución mexicana un siglo antes.

\section{A MODO DE CONCLUSIóN}

Una conclusión respecto del proceso político mexicano que tuvo lugar durante el gobierno presidido por EPN entre 2012 y 2018, elaborada sin la perspectiva que da la distancia en el tiempo, lleva a calificar ese sexenio como el extremo final de un arco histórico que se inició con la consolidación en el poder del grupo revolucionario encabezado por Venustiano Carranza, a inicios del siglo xx, y que desembocó en la formación de un exitoso sistema autoritario basado en una presidencia con pocos contrapesos, pero sin reelección, y sostenida por un ejército de su propia creación y un partido de Estado: el PRI.

Poco a poco y acicateado por una serie de crisis -la efímera guerrilla de Ciudad Madera, el movimiento navista, el 68, la Guerra Sucia, el fracaso del modelo económico del desarrollo estabilizador, entre otras-, el régimen se vio obligado a aceptar un pluralismo cada vez más amplio. Este proceso llegó al punto en que México transitó de elecciones sin contenido a otras de carácter competitivo, aunque aún tardó en lograr resultados con plena credibilidad.

La paulatina transformación del sistema autoritario mexicano en democrático se explica, en buena medida, por otras transformaciones: la de la sociedad -urbanización, educación, comunicaciones, entre otras-, sumada a la del entorno internacional: el surgimiento de la llamada "tercera ola democrática”, la globalización y el fin de la Guerra Fría. Esos procesos llevaron al sistema priista al punto en que se vio obligado a ceder, primero, espacios políticos secundarios y, finalmente, en el año 2000, la presidencia. La cesión se hizo en favor del competidor de derecha: el PAN. 
En 2012, el PRI recuperó el control de la presidencia, pero la presencia de una oposición ya arraigada, aunada a la ineficacia y corrupción de su administración, desembocó en 2018 en una segunda y más contundente derrota para un PRI que se había anunciado como "nuevo", pero también en la derrota de una derecha que había logrado convivir con el priismo sin muchas dificultades. La fuerza que superó en las urnas al PRI, al PAN y a sus aliados, se organizó bajo las siglas de un partido de reciente creación, Morena, pero muchos de cuyos cuadros dirigentes provenían, en buena medida, de organizaciones añejas: de una fractura sufrida por el PRI en la década de los ochenta, del Partido Comunista Mexicano y de otras agrupaciones que encontraron en el liderazgo carismático de Andrés Manuel López Obrador al dirigente que los aglutinó y que, además, pudo movilizar el apoyo de un sector pluriclasista y sin afiliación partidaria.

La síntesis aquí presentada de algunas de las políticas y circunstancias que moldearon al sexenio de EPN y los suyos no sólo resalta algunas de las razones que llevaron al fracaso el intento de hacer viable un supuesto "nuevo PRI" que, en realidad, no tuvo nada de nuevo, sino también las circunstancias que abrieron la posibilidad de que los sustitutos del peñanietismo se propusieran llevar adelante nuevas políticas sociales y económicas y, más aún, una modificación del régimen mismo. Desde luego, sólo el tiempo permitirá saber si tal empeño tuvo éxito y hasta qué punto.

\section{REFERENCIAS BIBLIOGRÁFICAS}

Aboites, Hugo, "IneE y cancelación de la reforma educativa", $L a$ Jornada, 21 de julio de 2018.

Astorga, Luis, ¿Qué querían que hiciera?, México, Grijalbo, 2015.

Barranco, Bernardo (coord.), El infierno electoral. El fraude en el Estado de México y las próximas elecciones de 2018. México, Grijalbo, 2018. 
Boullosa, Carmen y Mike Wallace, A Narco History: How the United States and Mexico Jointly Created the Mexican Drug War, Nueva York, OR Books, 2015.

Cantú, Guillermo H., Asalto a palacio. Las entrañas de una guerra, México, Grijalbo, 2001.

Casar, María Amparo y Luis Carlos Ugalde, Dinero bajo la mesa. Financiamiento y gasto ilegal de las campañas políticas en México, México, Grijalbo, 2018.

Centro de Estudios Sociales y de Opinión Pública, Ley Federal del Trabajo, propuestas de reforma, alcances y opinión pública, México, Cámara de Diputados del Congreso de la Unión, 2012.

Consejo Coordinador Empresarial, CCE, "Mensaje extraordinario, aprobación de la reforma laboral”, comunicado del 13 de noviembre de 2012.

Consulta Mitofsky, "Confianza en las instituciones, 2018", octubre de 2018.

Consulta Mitofsky, "Evaluación 23 trimestres de gobierno de Enrique Peña Nieto", 11 de noviembre de 2018.

Correa-Cabrera, Guadalupe, Los Zetas inc. Criminal corporations, energy and civil war in Mexico, Austin, University of Texas Press, 2017.

Crespo, José Antonio, 2006: hablan las actas. Las debilidades de la autoridad electoral mexicana, México, Random House Mondadori, 2008.

Crowley, Michael, "Saving Mexico. How Enrique Peña Nieto's sweeping reforms have changed the narrative in his narcostained nation", Time, 24 de febrero de 2014.

"Da a conocer INE resultados del cómputo de la elección presidencial 2018" (comunicado de prensa núm. 405), México, Central Electoral, Instituto Nacional Electoral, INE, https://centrale lectoral.ine. $\mathrm{mx} / 2018 / 07 / 06 /$ da-conocer-ine-resultados-delcomputo-de-la-eleccion-presidencial-2018/

Decreto por el que se reforman, adicionan y derogan diversas disposiciones de la Constitución Política de los Estados Unidos Mexicanos, en materia de combate a la corrupción, Diario Oficial de la Federación, 27 de mayo de 2015. 
"El PAN acusa al gobierno de Peña de usar recursos con fines políticos", Expansión, 17 de abril de 2013, expansion.mx/nacional/2013/04/17/el-pan-acusa-al-gobierno-de-pena-de-usar-re cursos-con-fines-politicos

Estévez, Dolia, "Exdirector de la cia: La agencia espía a líderes en México, 'nunca dijimos que se dejaría de hacer'”, Sin Embargo, 1 de noviembre de 2018, https://www.sinembargo.mx/01-112018/3490066

Gil Olmos, José, Las batallas de Michoacán, México, Ediciones Proceso, 2015.

Gobierno de la República, Reforma educativa. Resumen ejecutivo, www.gob.mx/cms/uploads/attachment/file/2924/Resumen_ Ejecutivo_de_la_Reforma_Educativa.pdf

Gobierno de la República, Reforma energética, https://www.gob. $\mathrm{mx} / \mathrm{cms}$ /uploads/attachment/file/10233/Explicacion_am pliada_de_la_Reforma_Energetical.pdf

Gómez Hermosillo, Rogelio, "Lucro político con la pobreza: las prácticas de compra y coacción del voto en las elecciones de 2018”, en Bernardo Barranco, AMLO y la tierra prometida. Análisis del proceso electoral de 2018 y lo que viene, México, Grijalbo, 2018, pp. 81-98.

Hernández, Anabel, La verdadera noche de Iguala: la historia que el gobierno trató de ocultar, México, Grijalbo, 2016.

Hernández, Rogelio, "El refugio del PRI durante la alternancia panista”, Foro Internacional, 55 (2015), pp. 45-82.

Instituto Federal Electoral, IFE, Secretaría Ejecutiva, "Cifras relevantes del proceso electoral 2011-2012”, México, 28 de junio de 2012.

Instituto Nacional de Estadística y Geografía, INEGI, "Datos preliminares revelan que en 2018 se registraron 35 mil 964 homicidios", comunicado de prensa 347/19, https://www.inegi.org. $\mathrm{mx} /$ contenidos/saladeprensa/boletines/2019/EstSegPub/ homicidios2018.pdf

Labastida Martín del Campo, Julio y Miguel Armando López LeYva, "México: una transición prolongada (1988-1996/97)", Revista Mexicana de Sociología, 66 (2004), pp. 761-762. 
LizÁrraga, Daniel et al., La casa blanca de Peña Nieto. La historia que cimbró un gobierno, México, Grijalbo, 2015.

López Obrador, Andrés Manuel, Neoporfirismo, hoy como ayer, México, Grijalbo, 2014.

Mariscal, Judith, Estudio sobre el mercado de televisión abierta, México, Telecom / cIDE, 2011.

Meyer, Lorenzo, Rafael Segovia y Alejandra Lajous, Historia de la Revolución mexicana, periodo 1928-1934. Los inicios de la institucionalización: la política del maximato, vol. 12, México, El Colegio de México, 1978.

Miles Valverde, José Manuel, Todos somos autodefensas: El despertar de un pueblo dormido, México, Grijalbo, 2017.

Mondragón Quintana, Juan Carlos, Financiamiento de partidos, rendición de cuentas y corrupción en México, México, Flacso, 2014.

Morales, Martha Gloria y Luis Alberto Fernández (coords.), La elección presidencial de México, 2012. Miradas divergentes, México, Fontamara, 2012.

Organización para la Cooperación y el Desarrollo Económicos, OCDE, "Nota país. Programa para la Evaluación Internacional de Alumnos, PISA, 2015. México”, https://www.oecd.org/pisa/ PISA-2015-Mexico-ESP.pdf

Pereyra, Guillermo, "México: violencia criminal y 'guerra contra el narcotráfico'”, Revista Mexicana de Sociología, 74 (2012), pp. 429-460.

Pérez Mendoza, Ana Lilia, Camisas azules, manos negras: el saqueo de Pemex desde Los Pinos, México, Grijalbo Mondadori, 2010.

Pérez Mendoza, Ana Lilia, Pemex RIP. Vida y asesinato de la principal empresa mexicana, México, Grijalbo, 2017.

Pew Research Center, “Mexican President Peña Nieto's Ratings Slip with Economic Reform”, Global Attitudes Survey, Q.44, primavera de 2014.

Pressly, Linda, "Cherán, el pueblo de México que expulsó a delincuentes, políticos y policías”, $B B C, 17$ de octubre de 2016, https://www.bbc.com/mundo/noticias-america-latina-37644 226

Quintanar, Héctor Alejandro, Las raíces del Movimiento Regeneración Nacional, México, Itaca, 2017. 
Ramírez Martínez, Benito, "El 'fracaso' del sistema de justicia penal acusatorio en México”, Hechos y Derechos (2017), núm. 40, https://revistas.juridicas.unam.mx/index.php/hechos-y-dere chos/article/view/11440/13340

Ramos, Rolando, "Impacta el periodo electoral en la aprobación del presidente", El Economista, 1 de marzo de 2018, https:/ / www.eleconomista.com.mx/politica/Impacta-el-periodo-elec toral-en-la-aprobacion-del-presidente-20180301-0153.html

Resultados nacionales 2015, Lenguaje y Comunicación, México, Instituto Nacional para la Evaluación de la Educación, INEE, 2015, http:// planea.sep.gob.mx/content/general/docs/2015/Pla neaFasciculo_9.pdf

"Revela SNTE su membresía", Reforma, 15 de mayo de 2017, citado por Mexicanos Primero, "Noticias de Hoy. Revela SNTE su membresía”, http://mexicanosprimero.org/index.php/educacionen-mexico/enterate/noticias-de-hoy/4289-revela-snte-su-mem bresia

RolDÁn, Nayeli, "Reforma Educativa no ha mejorado la educación, dice Auditoría; sEP acepta retrasos pero resalta mejoras", Animal Político, 22 de febrero de 2018, https://www.animalpoliti co.com/2018/02/reforma-educativa-no-mejoro-escuelas/

Senado de la República, Balance de las reformas estructurales [4 tomos], México, Instituto Belisario Domínguez / Senado de la República, LXIV Legislatura, 2018.

"Texto completo del Pacto por México", Animal Político, 3 de diciembre de 2012, https:/ / www.animalpolitico.com/2012/12/ los-cinco-acuerdos-del-pacto-por-mexico/

Ureste Cava, Manuel et al., La estafa maestra, México, Temas de Hoy, 2018.

Villamil, Jenaro, Cleptocracia. El nuevo modelo de corrupción, México, Grijalbo, 2018.

World Justice Project, México, "La nueva justicia penal en México. Avances palpables y retos persistentes", worldjusticeproject. mx/wp-content/uploads/2018/09/WJPMX-LaNuevaJusticia PenalMexico_.pdf 


\section{FUENTES HEMEROGRÁFICAS}

\section{Animal Político}

20 de junio de 2016.

7 de julio de 2016.

Aristegui Noticias

12 de marzo de 2014.

El Economista

27 de agosto de 2018.

El Financiero

9 de diciembre de 2019.

El País

26 de junio de 2018.

9 de octubre de 2018.

Excélsior

9 de junio de 2013.

28 de enero de 2015.

Forbes México

6 de abril de 2018.

25 de abril de 2018.

La Jornada

28 de enero de 2015.

13 de mayo de 2017.

13 de agosto de 2018.

Milenio

2 de agosto de 2018.

Proceso

23 de junio de 2012.

30 de noviembre de 2012.

3 de noviembre de 2013.

22 de julio de 2018.

Semanario Zeta

23 de noviembre de 2012.

Sin Embargo

22 de abril de 2017. 
